\title{
Nome próprio e descrição do social: poética da nomeação em Balzac ${ }^{*}$
}

\section{Proper Name and Social Description: Balzac's Poetics of Naming}

\author{
Raquel Campos \\ raquelmgcampos@gmail.com \\ Pós-doutoranda \\ Universidade Federal de Goiás \\ Campus Samambaia - Caixa Postal 131 \\ 74001-970 - Goiânia - GO \\ Brasil
}

\section{Resumo}

Uma figura sintetiza a dimensão do projeto literário balzaquiano: "fazer concorrência ao registro civil". Ela expressa a medida da inédita ambição realista de que Balzac dotou o gênero do romance, ao conferir-lhe o poder de descrever o social. Ela também indica o lugar central que o nome próprio tomou em A comédia humana como história da França no século XIX. O objetivo deste artigo é analisar a poética da nomeação em Balzac, examinando as funções do nome próprio em sua obra e o modo como ele nomeou suas personagens. Minha hipótese é a de que o romancista constitui um capítulo fundamental da história da onomástica literária: com ele, o nome próprio tornou-se uma questão capital do romance e a motivação impôs-se como um verdadeiro topos literário.

Palavras-chave

Realismo; Século XIX; Onomástica.

\section{Abstract}

An expression summarizes the dimension of Balzac's literary project: "to compete with the civil registry." On the one hand, it provides a measure of the unprecedented realistic ambition with which Balzac has marked the genre of the novel, by giving it the power to describe the society. On the other, it also indicates the central place attributed to the proper name in The Human Comedy as a history of France in the $19^{\text {th }}$ century. The purpose of this article is to analyze the poetics of naming in Balzac, examining the functions of the proper name in his work and the way he named his characters. My hypothesis is that the novelist has become a key chapter in the history of literary onomastics: with him, the proper name has become a fundamental issue in the novel, while its motivation has imposed itself as a true literary topos.

\section{Keywords}

Realism; $19^{\text {th }}$ century; Onomastic.

\author{
Recebido em: 3/8/2014
}

Aprovado em: 11/9/2014

\footnotetext{
* Esta pesquisa contou com o financiamento da Coordenação de Aperfeiçoamento de Pessoal de Nível Superior (CAPES).
} 
Em seu esforço para estabelecer uma análise estrutural da narrativa, a teoria literária tomou como um de seus alvos a compreensão da personagem. Condenando a confusão entre as noções de "pessoa" e "personagem", ela postulou a necessidade de se compreender esse último tendo como único universo de análise a narrativa em que está inserido e de analisá-lo do ponto de vista das ações de que é o sujeito. No que concerne ao problema do significante do personagem, mais especificamente de seu nome próprio, chamou-se a atenção para a possibilidade de ele ser motivado, enfatizando-se sua diferença em relação ao nome próprio em geral (HAMON 1977; RIGOLOT 1977).

Como signo linguístico, o nome próprio singulariza-se por ser desprovido de sentido, portanto, de relação de significação (estabelecida entre significante e significado), a ele sendo reservada a relação de denotação (estabelecida entre a palavra e o objeto). Sua função é a identificação pura: distinguir e individualizar uma pessoa ou coisa. Mas em literatura, destacou a teoria literária, o nome próprio pode ser dotado de significado, isto é, ser motivado. Nesse sentido, ele entrará em relação com a personagem designada, de maneira harmônica ou antifrástica (RIGOLOT 1977, p. 11-12).

Tal modo de abordar a onomástica literária, se tem o mérito de superar análises puramente referenciais, que se restringiam a buscar no fora-do-texto as fontes biográficas ou geo-históricas dos antropônimos literários, por outro lado, conduz frequentemente a desconsiderar a historicidade das práticas de nomeação das personagens. Com efeito, ao contrário do que as análises baseadas na teoria literária tendem a sugerir - e, em todo caso, aquilo que elas esquecem -, os autores nem sempre nomearam suas personagens da maneira como o fazem atualmente. Eles nem sempre entenderam, como passaram a conceber a partir do século XIX, que o "nome próprio é uma coisa capital" em um romance, segundo a célebre frase de Gustave Flaubert; nem sempre praticaram a nomeação motivada, atribuindo um significado aos nomes de suas personagens, relacionado com os caracteres que lhes deram ou o destino que Ihes reservaram; nem sempre se utilizaram dos nomes correntes para batizar os filhos de sua imaginação; e até nem sempre os batizaram; e nem sempre puderam batizá-los livremente.

Do mesmo modo, o privilégio conferido à análise dos nomes dos personagens em uma obra específica favorece o obscurecimento das relações entre a onomástica literária e a poética do romance. Em sua permanente luta com seu próprio estatuto, não foi apenas o próprio gênero que se modificou, mas também a nomeação das personagens. Assim, no romance setecentista, a ambição de verossimilhança não apenas conduziu à emergência do romance-memória e do romance epistolar, nesse movimento paradoxal em que o privado, ao ser exibido, tornou-se garantia de verdade do relato (GOULEMOT 1991): tal ambição gerou igualmente um fenômeno de recusa generalizada da nomeação, que levou, por um lado, à designação das personagens por meios de iniciais ou de asteriscos e, por outro, à consolidação de nomes realistas, isto é, 
retirados da onomástica corrente ou inventados segundo sua lógica. ${ }^{1}$ No século XIX, com a emergência do romance realista e a correlativa atribuição ao gênero do poder de descrever o social, a onomástica literária sofreu nova alteração: passou a ter uma extensão inaudita e a ocupar um lugar central, e a motivação se transformou em topos literário. Essa tripla modificação é inseparável, por sua vez, de outro nome próprio: Honoré de Balzac.

\section{Concorrência ao registro civil}

Em Balzac, a nomeação das personagens impõe-se, em primeiro lugar, como uma questão de quantidade. Foi sob o signo do número que elas apareceram no "Prefácio" (1842) de A comédia humana: "o drama de três ou quatro mil personagens que a sociedade contemporânea apresenta", "as duas ou três mil figuras salientes de uma época". Em 1761, Diderot (1800, p. 220) impressionara-se com a capacidade de criação de Richardson, com as trinta ou quarenta personagens de seu mais famoso romance epistolar, Clarissa; menos de um século mais tarde, elas deviam elevar-se - e elevaram-se - a milhares na obra balzaquiana. Essa multiplicação inaudita não era o resultado natural de uma longa e profícua vida dedicada aos mais diversos gêneros literários, mas sim o fruto de um propósito: ela respondia ao desejo de "fazer concorrência ao registro civil" (BALZAC 1842, p. 13). A comédia humana pretendeu ser uma história completa da França contemporânea; seu escopo foi o mesmo do registro civil: a totalidade do real.

No tempo de Balzac, como mostrou Judith Lyon-Caen (2006, p. 30), o romance deixava de se consagrar à pintura dos vícios e das virtudes (marca do gênero no século XVIII), para se dotar de um objetivo muito mais ambicioso: retratar a sociedade contemporânea. O realismo não foi uma invenção $a$ posteriori da crítica social ou marxista, desejosa de transformar toda e qualquer literatura em instrumento de conhecimento e representação do mundo. Certo, nem toda literatura é realista; contudo, em um momento de sua história, ela o foi, definindo-se como uma forma de saber do "social", pretensão que uma perspectiva histórica de análise deve necessariamente levar em conta. Assim, ao invés de adotar a posição contrária, dominante com o estruturalismo e a teoria literária, segundo a qual toda literatura se define pela intransitividade da linguagem, é preciso considerar que o realismo foi um projeto dos próprios romancistas das décadas de 1830 e 1840 e que eles fizeram do romance não mais um veículo para o retrato das paixões, e sim para a representação dos costumes, dos tipos, do "social" - em seu duplo sentido de "sobre a sociedade" e "sobre as classes populares" (LYON-CAEN 2006, p. 30-31).

A virada em direção ao "social" coincidiu com o triunfo do gênero - tanto do ponto de vista da legitimidade quanto da predominância editorial - e pode ser apreendida em vários planos: nos programas expostos nos prefácios das obras e nas próprias narrativas, mas também, e de modo mais evidente, na designação

\footnotetext{
${ }_{1}^{1}$ Para uma discussão mais pormenorizada da onomástica romanesca no século XVIII, permito-me remeter ao segundo capítulo de minha tese de doutorado, "Os nomes (im)próprios do romance" (CAMPOS 2014, p. 67-122).
} 
mesma do gênero (LYON-CAEN 2006, p. 29-30). Ainda uma vez, as mutações do romance afetaram o seu nome. Assim, se já não se chamava de "história", "memória" ou "carta", ele tampouco se chamou apenas de romance. No segundo quartel do século XIX, "estudos sociais" e "romance social" tornaram-se expressões correntes, utilizadas tanto pelos editores, em seus anúncios, quanto pelos escritores, nos títulos e subtítulos de suas obras, afirmando-se desse modo "um vasto programa de 'romanceação' da sociedade contemporânea". Isso constatou-se no caso de O judeu errante (Le Juif errant) e Martin, o enjeitado (Martin l'enfant trouvé), ambos de Eugène Sue, anunciados nos jornais como "romance social", ou com $A$ pele de onagro (La peau de chagrin), de Balzac, publicado em sua edição de 1838 com o subtítulo "estudos sociais", só para citar alguns exemplos (LYON-CAEN 2006, p. 30). A obra de Balzac é especialmente significativa dessa mudança na ordem da designação: em 1834 - oito anos antes da publicação de $A$ comédia humana -, ele reuniu seus romances sob o título "Estudos de costumes no século XIX", invertendo a lógica habitual em que a indicação genérica esclarece o título, para fazer de cada romance parte de um projeto maior, definido em relação a uma extensão temporal, o "século XIX" (LYON-CAEN 2006, p. 31). Do mesmo modo, organizou mais tarde sua obra em "Estudos" e "Cenas", compostos cada um deles por um grande número de romances.

O autor de Ilusões perdidas encarnou, melhor do que ninguém, essa ambição de sua época, ao tentar escrever sozinho uma história normalmente tomada como o feito do romance como gênero ou como o produto de vários romances diferentes (LYON-CAEN 2006, p. 31). Naquele momento, era uma pretensão bastante escandalosa para um romancista e, por ela, Balzac tornou-se objeto de insultos e de escárnio. Isso explica seu empenho em justificar e explicar seu projeto - em curso de elaboração - nos vários prefácios das primeiras edições de suas obras (LYON-CAEN 2006, p. 34). Destinados ao desaparecimento, eles foram efetivamente suprimidos quando da edição de $A$ comédia humana (1842) e substituídos por um único paratexto inicial.

A comédia humana foi o novo nome de um projeto que vinha sendo gestado desde o final dos anos 1820 e que sofreu modificações importantes ao longo da década de 1830 (BALZAC 2000b, p. 82-84). As primeiras tentativas de Balzac no sentido de pensar um conjunto articulado de obras datam de 1824, quando ele estabeleceu o plano de uma Histoire de France pittoresque. O jovem escritor planejava então uma série de romances históricos que tomariam por tema um acontecimento emblemático de cada um dos séculos da história nacional (VACHON 2000, p. 17). Walter Scott já emergia como a grande referência de Balzac, que o elogiou por sua capacidade de exibir o espírito de um século, exprimir em apenas uma cena o gênio e a fisionomia de uma época. Com Scott, em palavras do romancista, "a história se torna doméstica" (BALZAC 2000a, p. 63). Assumindo-o como seu modelo, Balzac anunciou seu propósito de fazer da história mais do que um "esqueleto cronológico", num projeto inseparável de sua própria transformação em "historiador". Contada pelo romance, ela se apresentaria em "quadros de gênero", retratando os fatos ignorados dos costumes e usos nacionais (BALZAC 2000a, p. 66). Ao longo da década de 
1830, o romancista abandonou a ideia de estudar os séculos passados em prol de um enquadramento contemporâneo de seu projeto literário: seus Estudos sociais deveriam contar a história dos costumes no século XIX (BALZAC 2000b, p. 82). Balzac (sob seu próprio nome ou por intermédio de Philarète Chasles e de Félix Davin $)^{2}$ elaborou e reelaborou os contornos dessa história nos prefácios de várias obras da década de 1830, usados para apresentá-los, defender-se das críticas e solicitar condescendência com uma obra em curso, cujo sentido só seria plenamente compreensível uma vez que estivesse completa. Em lugar de seguir um encadeamento cronológico, a obra foi apresentada a partir de então como um monumento, um edifício composto por três planos: os "Estudos de costumes", os "Estudos filosóficos" e os "Estudos analíticos" (BALZAC 1842, p. 28). A "história geral da Sociedade" seria contada nos primeiros, por meio de seis tipos de "cenas". Elas deveriam permitir o conhecimento da realidade apresentando uma pintura das diferentes épocas da vida humana ("Cenas da vida privada") e por meio de uma oposição entre Paris e a província ("Cenas da vida provinciana" e "Cenas da vida parisiense"). Além desses quadros da vida social, as "Cenas da vida política" retratariam "as existências excepcionais que resumem os interesses de vários", enquanto as "Cenas da vida militar" tratariam dessa sociedade em guerras de defesa e de conquista, após as quais viria o entardecer do drama social nas "Cenas da vida rural". Todas essas cenas constituíam os "cenários" ou as "galerias" em que apareciam as "duas ou três mil figuras salientes de uma época" (BALZAC 1842, p. 27).

Em relação ao projeto balzaquiano, importa perceber, por outro lado, que o registro civil não é apenas o arquivo de todas as existências reais. Ele é aquele no qual a existência passa pela atribuição do nome próprio - donde sua importância para o problema da onomástica romanesca. No uso dessa figura específica, desvenda-se o desejo balzaquiano de chamar a atenção para o poder supremo que ele se arroga: nomear. Para o historiador-romancista, apenas o assentamento real de todos os nomes oferecia um termo de comparação com sua atividade onomatúrgica.

De fato, embora Balzac, segundo sua irmã Laure Surville (1858, p. 181182), tenha lançado mão de nomes existentes, pois "pretendia que os nomes inventados não conferiam vida aos seres imaginários, ao passo que aqueles que foram realmente usados dotavam-nos de realidade", ${ }^{3}$ o romancista foi principalmente um "fazedor de nomes". ${ }^{4}$ Naquele que foi provavelmente um dos primeiros textos sobre a nomeação em Balzac, Spoelberch de Lovenjoul sugeriu inclusive a existência, na França do século XIX, de uma relação intrínseca entre a invenção de personagens e a de seus antropônimos. Para ele, a utilização de

\footnotetext{
${ }^{2}$ Escritores e amigos de Balzac, Philarète Chasles e Félix Davin assinaram prefácios para obras balzaquianas. O primeiro escreveu a "Introdução" para a segunda edição de $A$ pele de onagro, que saiu em 1831 como parte dos Romances e contos filosóficos. Davin foi o autor, notadamente, das introduções para os Estudos filosóficos (1834) e para os Estudos de costumes (1835). Há indícios fortes de que Balzac tenha intervido diretamente nesses textos, em especial naqueles assinados por Davin. Ver, a esse respeito, VACHON (2000).

${ }^{3}$ No original: "Il avait une singulière théorie sur les noms; il prétendait que les noms inventés ne donnent pas la vie aux êtres imaginaires, tandis que ceux qui ont réellement été portés les douent de réalité".

${ }^{4}$ Do título do artigo de Claude Duchet (1999). Devo esta e outras referências sobre o problema do nome próprio em Balzac a Jérôme David, a quem endereço meus agradecimentos.
} 
nomes verdadeiros para batizar seres ficcionais só poderia se explicar por um esgotamento do estoque de nomes inventáveis - ou porque os escritores se mostrassem menos hábeis para inventar nomes, ou porque o número de romances publicados nos últimos anos havia sido excessivo. Fosse como fosse, o fato era para Lovenjoul incontestável, dados os embaraços causados pela necessidade de alterar os nomes das personagens em obras em curso de impressão ou quando de sua reimpressão e até mesmo em peças em cartaz, porque seus portadores verdadeiros teriam se queixado e exigido a substituição. Seriam tantos os problemas causados pela incapacidade de criar "qualificativos imaginários" que um escritor teria aventado a hipótese de suprimir os nomes próprios, designando suas personagens por números (LOVENJOUL 1973, p. 113-115). ${ }^{5}$

Essa seria uma incapacidade desconhecida para Balzac, sugeriu Lovenjoul sem (precisar) dizê-lo; com efeito, o autor de Eugênia Grandet engendrou ainda mais nomes do que aqueles que aparecem em A comédia humana. Ele tinha o hábito de anotar os que poderia vir a empregar em suas narrativas, e, entre eles, identificaram-se vários nunca utilizados (LOVENJOUL 1973, p. 129). Esses antropônimos balzaquianos não surgiram do nada. Uma de suas principais fontes foi o Armorial de familles nobles de la France, no qual o romancista selecionou sobrenomes dessuetos, alterando ligeiramente sua ortografia. Outro procedimento consistia na conversão de nomes de lugares em sobrenomes: Langeais, nome da heroína do segundo episódio de História dos Treze (Histoire des Treize), denominara originalmente um solar da região de Tours; Négrepellise, de Anaïs, de Ilusões perdidas era o nome de uma cidade do departamento de Tarn-et-Garonne (LOVENJOUL 1973, p. 121-122); Saint-Herém e Morillon, que figuram na "Advertência" ao Gars, ${ }^{6}$ designariam uma cruz e um monte na região entre Fontainebleau e Nemours - mas Morillon poderia ter sido aproveitado a partir do sobrenome de um professor de gramática do Colégio Vendôme, o que o enquadraria em outra categoria de nomes e desvela o caráter um tanto conjectural desse tipo de exercício (POMMIER 1953, p. 225). Identificou-se igualmente a manipulação de nomes verdadeiros: do bispo de Pamiers, Henry de Sponde (1568-1643), originaram-se o vidama de Pamiers e o abade de Sponde (LOVENJOUL 1973, p. 124). Balzac não costumava usar os nomes correntes sem introduzir alguma alteração: de Gambaro, o escritor fez Gambara; de Merville, Derville; de Lebas, Lepas; de Dutacq, Dutocq (POMMIER 1953, p. 227).

Muitos outros nomes imaginários e inéditos foram identificados em folhas nas quais Balzac anotara também os títulos das obras às quais os destinava prática cuja descoberta corrobora o juízo de Lovenjoul (1973, p. 116): "Ninguém, em nosso século, preocupou-se tanto com a questão dos nomes quanto Honoré de Balzac". De tal preocupação, entretanto, talvez não fosse necessário qualquer outro testemunho senão a própria obra monumental do escritor.

\footnotetext{
${ }^{5}$ O conde Spoelberch de Lovenjoul (1836-1907) foi um grande colecionador de romances, revistas, jornais, manuscristos, correspondências, etc. ligados à literatura francesa oitocentista. Ele conseguiu reunir a maior parte dos manuscritos e provas corrigidas de Balzac, dispersados quando da morte da viúva, Madame Hanska. Em 1905, doou sua coleção para o Institut de France, onde ela se encontra atualmente.

6 Título de um romance projetado, mas nunca redigido por Balzac, que apenas elaborou seu prefácio, a "Advertência", na qual Le Gars foi atribuído a Victor Morillon. O manuscrito desse texto foi encontrado entre os esboços e fragmentos conservados da Histoire de France pittoresque (VACHON 2000, p. 48-49).
} 
Com efeito, o nome próprio encontra-se no centro de $A$ comédia humana. Parte fundamental do empreendimento de descrição do social, de construção de uma "sociedade ficcional que ser[ia] como um mundo completo", o nome das personagens foi reinvestido de importância quando Balzac rompeu com o romance como unidade fechada, ao inventar um procedimento que teria fortuna importante não só na literatura francesa - e ao qual se associaram nomes como Émile Zola7 ou Marcel Proust -, mas cujas repercussões puderam também ser identificadas em Machado de Assis (PASSOS 2006): o chamado retorno das personagens, experimentado pela primeira vez em O pai Goriot (1836). Cada nome próprio libertava-se do quadro de uma narrativa para reaparecer em outros romances, outras "cenas", reforçando a poética contrastiva que o escritor adotou (DAVID 2010, p. 62). Também esse procedimento foi por ele justificado em termos realistas:

Os personagens de cada história movimentam-se em uma esfera que não tem outra circunscrição senão a da própria sociedade. Quando uma dessas personagens se encontra, como M. de Rastignac no PAI GORIOT (PÈRE GORIOT), suspenso no decurso de sua existência, é que deveis reencontrá-lo em Perfil de marquesa (Profil de marquise), em A interdição (L'Interdiction), em $O$ alto banco (La haute banque) e, enfim, em $A$ pele de onagro, agindo em sua época segundo a posição que assumiu e participando de todos os acontecimentos dos quais participam, na realidade, os homens dotados de um alto valor. Essa observação aplica-se a quase todas as personagens que figuram nessa longa história da sociedade: as personagens eminentes de uma época não são assim tão numerosas quanto se poderia acreditar, e não haverá menos de mil nesta obra que, em um primeiro esboço, deve ter vinte e cinco volumes - em sua parte mais descritiva, é verdade; sob esse ponto de vista, ela será fiel (BALZAC 1837, p. VI-VII, tradução nossa). ${ }^{8}$

Ora, ainda que um nome não designe necessariamente uma só personagem, o retorno das personagens não pode ser outro senão o retorno do nome. As reescritas e discussões suscitadas pelo romance que viria a se chamar $A$ mulher de trinta anos (La femme de trente ans) oferecem bem a medida do caso. Em 1834, Balzac reuniu, sob o título Mesma história (Même histoire), a inédita Sofrimentos desconhecios (Souffrances inconnues) e as cinco novelas Encontro (Rendez-vous), A mulher de trinta anos, O dedo do Deus (Le Doigt de Dieu), Dois encontros (Deux rencontres) e Expiação (Expiation), parte das quais já

\footnotetext{
7 Cabe observar que, em Os Rougon-Macquart, Zola não praticou rigorosamente o retorno balzaquiano das personagens, pois contou a história de uma única família sob o Segundo Império, desdobrada em vinte romances diferentes (LEONARD 1980, p. 85).

${ }^{8}$ No original : "Les personnages de chaque histoire se meuvent dans une sphère qui n'a d'autre circonscription que celle même de la société. Quand un de ces personnages se trouvent como M. de Rastignac dans le PĖRE GORIOT, arrêté au milieu de sa carrière, c'est que vous devez le retrouver dans Profil de marquise, dans I'Interdiction, dans La haute banque, et enfin dans la Peau de Chagrin, agissant dans son époque suivant le rang qu'il a pris et touchant à tous les événements auxquels les hommes qui ont une haute valeur participent en réalité. Cette observation s'applique à presque tous les personnages qui figurent dans cette longue histoire de la société: les personnages éminents d'une époque ne sont pas aussi nombreux qu'on peut le croire, et il n'y aura pas moins de mille dans cette oeuvre qui, au premier aperçu, doit avoir vingt-cinq volumes, dans sa partie la plus descriptive il est vrai; sous ce rapport, elle sera fidèle". Profil de marquise foi o novo título dado por Balzac para Estudo de Mulher [Étude de femme], quando de sua segunda edição, nos Estudos de costumes do século XIX, em maio de 1835. Em sua quarta edição, ao integrar-se à Comédia Humana, o romance recuperou seu título original. Já La haute banque era o título original de $A$ Casa Nucingen [La Maison Nucingen], uma das Cenas da vida parisiense.
} 
havia sido publicada e republicada em revistas e livros e havia sido revisada e aumentada para aquela edição. Dois anos antes, elas haviam saído na segunda edição de Cenas da vida privada, sem título comum, numeradas como "Cenas" $11,12,13,14$ e 15 e antecedidas por uma "Nota do editor" assinada por Mame-Delaunay, na qual ele as apresentava como o "esboço de uma vida de mulher [...], uma mesma personagem disfarçada sob cinco nomes diferentes" (MILLER). Além de dar um título comum à obra, adotado para aquela terceira edição de Cenas da vida privada (1834), Balzac (1834, p. 7-9) substituiu a "Nota do editor" por um "Prefácio" - os Estudos de costumes no século XIX saíam então pela casa Madame Charles-Béchet, o que explica a necessidade de suprimir a nota de Mame-Delaunay. A relação entre nome e personagem permanecia inescapável, já que as heroínas das novelas continuavam tendo nomes diferentes e uma delas era anônima. Balzac não se esquivou do problema, abordando essa questão logo de saída. O decidido conselho de leitura da edição anterior foi trocado por uma interrogação indireta: "Muitas pessoas me perguntaram se a heroína de ENCONTRO, de A MULHER DE TRINTA ANOS, de DEDO DE DEUS, dos DOIS ENCONTROS e de A EXPIAÇÃO não era, sob diversos nomes, a mesma personagem". Se Balzac reconhecia, assim, a atribuição ao autor da responsabilidade de decidir, ele negou-se a responder, transferindo o encargo ao título: "O autor não pode dar nenhuma resposta a essas questões. Mas talvez meu pensamento seja expresso no título que reúne essas diferentes cenas". Em seguida, ao suspender o estatuto habitual da personagem, revelou a relação intrínseca entre o nome e o pessoal romanesco:

O personagem que atravessa, por assim dizer, esses seis quadros dos quais se compõe MESMA HISTÓRIA não é uma figura; é um pensamento. Quanto mais esse pensamento se reveste de costumes dessemelhantes, melhor expressa ele as intenções do autor. Sua ambição é comunicar à alma a vaga de um devaneio em que possam ser despertadas algumas das mais vivas impressões que as mulheres conservaram, reanimadas as lembranças espalhadas pela vida, para delas fazer surgir alguns ensinamentos (BALZAC 1834, p. 7-9, tradução nossa). ${ }^{9}$

$\mathrm{Na}$ "Introdução" que escreveu aos Estudos de costumes do século XIX (1835), Félix Davin (1835, p. 22-23) tratou desse singular procedimento de seu prefaciado. Após dar notícia de sua má recepção (ou seria argumento retórico desse prefaciador escrevendo sob as orientações de Balzac?) - "algumas pessoas lamentaram que as cenas [...] não tenham entre si outra ligação senão um pensamento filosófico" -, ele afirmou concordar, ao menos parcialmente, com as restrições feitas. A argumentação de Davin passou por estabelecer a singularidade das "obras de imaginação" face "às obras de espírito", porquanto aquelas, por mais

\footnotetext{
${ }^{9}$ No original: "Plusieurs personnes m'ont demandé si l'heroïne du RENDEZ-VOUS, de LA FEMME DE TRENTE ANS, du DOIGT DE DIEU, des DEUX RENCONTRES et de L'EXPIATION, n'était pas, sous divers noms, le même personnage. L'auteur n'a pu faire aucune réponse à ces questions. Mais peut-être sa pensée sera-t-elle exprimée dans le titre qui réunit ces différentes scènes. Le personnage qui traverse pour ainsi dire les six tableaux don se compose MÊME HISTOIRE n'est pas une figure; c'est une pensée. Plus cette pensée y rêvet des costumes dissemblables, mieux elle rend les intentions de l'auteur. Son ambition est de communiquer à l'âme le vague d'une reverie où les femmes puissent réveiller quelques unes des vives impressions qu'elles ont conservées, de ranimer les souvernirs épars dans la vie pour en faire surgir quelques enseignements".
} 
elevadas que fossem, não poderiam interessar recorrendo simplesmente a "uma sucessão bem lógica de ideias, uma fraternidade bem sentida de princípios"; era preciso falar também ao coração e à imaginação. E só o feitiço de uma personagem seria capaz de seduzir esses últimos; substituí-la a cada capítulo ou obrigar a ler o livro todo para então reconhecer sua heroína era, para ele, uma escolha perigosa. "O autor arrisca-se a ser mal compreendido", concluiu.

Expressasse Davin ou não dúvidas do próprio romancista, o fato é que, nos anos seguintes, Balzac voltou a revisar aquelas novelas. Na edição Werdet das Cenas da vida privada (1837), o título comum e o prefácio foram suprimidos, e o sistema de retorno de personagens foi adotado para as personagens secundárias, o que significou alterar o nome de algumas e eliminar outras, sem contar outras alterações nos textos. Após uma reedição do texto de 1834 na publicação in-18 que Charpentier fez das Cenas da vida privada (1839), a opção pela coincidência entre nome e personagem se impôs no momento chave que foi a organização de $A$ comédia humana (1842). Julie d'Aiglemont tornou-se a única heroína de todas as narrativas, que, comandadas destarte pelo nome, transformaram-se em capítulos de um novo romance, $A$ mulher de trinta anos (MILLER).

Mas a ênfase balzaquiana em seu poder de nomear compreende-se, ainda, para além das duas propriedades da multiplicação e do retorno, que fazem do nome próprio peça fundamental do esforço de descrição exaustiva das "espécies sociais" da França contemporânea e garantia da unidade da obra, de sua existência como sistema - Balzac considerava que a única restrição possível a Walter Scott era o fato de ele não ter buscado "ligar suas composições umas às outras a fim de fazer uma história completa" (BALZAC 1842, p. 10; 14).

\section{Cognomologia}

No século XVIII, um discurso sobre os nomes das personagens tomou o paratexto dos romances a fim de contribuir para a verossimilhança de uma narrativa dada como texto não ficcional, cujas personagens estariam vivas ou teriam morrido havia pouco. Ao longo do século, esse discurso refluiu para apenas ficarem os nomes inventados e realistas que não convocavam nenhuma decifração, nenhum leitor mais competente. ${ }^{10}$ Com Balzac, os nomes voltaram a ser assunto, mas já então no interior mesmo dos romances. A atenção do narrador balzaquiano voltou-se para eles antes mesmo da adoção do retorno das personagens. Em A pele de onagro, Rafael, enfeitiçado pelo nome de Foedera, pôs-se a imaginar a que tipo de mulher ele deveria corresponder:

Como explicar o fascínio de um nome? Foedera me perseguiu como um mau pensamento que procuramos transigir. Uma voz me dizia: você irá à casa de Foedera. Era inútil debater-me com ela e gritar-Ihe que mentia, ela esmagava todos os meus argumentos com esse nome: Foedera. Mas esse nome, essa mulher não seriam eles o símbolo de todos os meus desejos e o tema da minha vida? O nome despertava as poesias artificiais do mundo, fazia brilhar as festas da grande Paris e os ouropéis

${ }_{10}$ Para uma discussão do problema do nome próprio no romance setecentista, permito-me remeter ao segundo capítulo de minha tese de doutorado, "Os nomes (im)próprios do romance". Cf. CAMPOS 2014. 
da vaidade; a mulher me aparecia com todos os problemas de paixão que me enlouqueciam. Talvez não fosse nem a mulher nem o nome, mas todos os meus vícios que se levantavam em minha alma para novamente me tentar. A condessa Foedera, rica e sem amante, resistente às seduções parisienses, não seria a encarnação das minhas esperanças, das minhas visões? Eu me inventava uma mulher, desenhava-a em meu pensamento, sonhava com ela. Durante a noite, não dormi, tornei-me seu amante, fabriquei em poucas horas toda uma vida, uma vida de amor; saboreei suas fecundas, brilhantes delícias (BALZAC 1845, p. 84, tradução nossa). ${ }^{11}$

Em outros romances da década de 1830, a questão do nome das personagens apareceu associada a outro nome próprio, um nome de autor: Laurence Sterne. Assim, em Gobseck, o narrador assinalou, a respeito da personagem epônima: "Enfim, por uma singularidade que Sterne chamaria uma predestinação, esse homem denominava-se Gobseck" (BALZAC 1842, p. 379, tradução nossa). ${ }^{12} \mathrm{Em}$ A procura do absoluto, Balthazar de Claës disse a sua filha Marguerite, em quem depositava as esperanças de reconstrução da fortuna da família:

- Vá, disse-lhe ele, em seis meses encheremos isso de ouro e de maravilhas. Você será como uma rainha. Bah! Toda a natureza nos pertencerá, nós estaremos acima de tudo... e por você... minha Marguerite. Margarita? repetiu ele, sorrindo, seu nome é uma profecia. Margarita quer dizer uma pérola. Sterne disse-o em algum lugar. Você leu Sterne? Quererá você um Sterne? Ele a divertirá (BALZAC 1845, p. 431, tradução nossa). ${ }^{13}$

E em O cura de Tours, a narração sobre a conversa que se seguiu à entrevista de César Birotteau com o advogado da senhorita Gamard, no salão da Senhora de Listomère, é interrompida por esta observação:

Aqui, o historiador teria o direito de delinear o retrato dessa senhora. Pensou, porém, que mesmo aqueles que ignoram o sistema da cognomologia de Sterne não poderiam pronunciar estas três palavras:

\footnotetext{
${ }_{11}$ No original: "Comment expliquer la fascination d'un nom ? Foedera me poursuivit comme une mauvaise pensée avec laquelle on cherche à transiger. Une voix me disait : Tu iras chez Foedora. J'avais beau me débattre avec cette voix et lui crier qu'elle mentait, elle écrasait tous mes raisonnements avec ce nom : Foedora. Mais ce nom, cette femme n'étaient-ils pas le symbole de tous mes désirs et le thème de ma vie ? Le nom réveillait les poésies artificielles du monde, faisait briller les fêtes du haut Paris et les clinquants de la vanité ; la femme m'apparaissait avec tous les problèmes de passion dont je m'étais affolé. Ce n'était peutêtre ni la femme ni le nom, mais tous mes vices qui se dressaient debout dans mon âme pour me tenter de nouveau. La comtesse Foedora, riche et sans amant, résistant à des séductions parisiennes, n'était-ce pas l'incarnation de mes espérances, de mes visions ? Je me créai une femme, je la dessinai dans ma pensée, je la rêvai. Pendant la nuit je ne dormis pas, je devins son amant, je fis tenir en peu d'heures une vie entière, une vie d'amour ; j'en savourai les fécondes, les brûlantes délices". Essa edição baseia-se na chamada "edição Furne", que vem a ser a original de A Comédia Humana, publicada entre 1842 e 1855 . Nela, A pele de onagro ocupa o volume 14, o primeiro dos "Estudos filosóficos", publicado em 1845. O trecho em questão possui poucas diferenças em relação àquele da primeira versão do romance, publicado em 1831 com o subtítulo "Romance filosófico" (TOURNIER).

${ }^{12}$ No original: "Enfin, par une singularité que Sterne appellerait une prédestination, cet homme se nommait Gobseck". Entre 1830, data de sua aparição nas Cenas da vida privada, e 1842, quando foi publicado no segundo volume de $A$ comédia humana, o texto sofreu algumas alterações; a referência a Sterne, por sua vez, já aparecia na edição original, cujo título era Les dangers de l'inconduite (MALEUVRE).

13 No original: "- Va, lui dit-il, dans six mois, nous remplirons ça d'or et de merveilles. Tu seras comme une reine. Bah ! la nature entière nous appartiendra, nous serons au-dessus de tout... et par toi... ma Marguerite. Margarita ? reprit-il en souriant, ton nom est une prophétie. Margarita veut dire une perle. Sterne a dit cela quelque part. As-tu lu Sterne ? veux-tu un Sterne ? ça t'amusera". O romance foi originalmente publicado em setembro de 1834, no terceiro volume dos Estudos de costumes no século XIX, como uma das "Cenas da vida privada". Balzac efetuou poucas intervenções no texto até sua publicação no quadro de $A$ comédia humana - 0 diálogo de Claës com sua filha Marguerite permaneceu intacto (FRAPPIER-MAZUR).
} 
SENHORA DE LISTOMÈRE sem retratá-la nobre, digna, temperando os rigores da devoção pela antiga elegância dos costumes monárquicos e clássicos, por maneiras corteses; boa, mas um pouco áspera; levemente fanhosa; permitindo-se a leitura da Nova Heloísa, o teatro e preocupando-se ainda com o penteado (BALZAC 1990a, p. 530). ${ }^{14}$

A referência se manteve na década de 1840, quando Balzac escreveu Úrsula Mirouët, uma das cenas da vida provinciana. Ali, após traçar longamente o retrato físico do chefe da posta de Nemours, o narrador voltou-se para seu caráter:

Filho da Revolução e espectador do Império, Minoret-Levrault nunca se imiscuíra na política. Quanto às suas opiniões religiosas, nunca pusera os pés na igreja, a não ser para casar-se. Seus princípios na vida privada estavam fixados no Código Civil: tudo o que a lei não proibia ou não podia atingir, ele julgava realizável. Nunca havia lido mais que o jornal do departamento de Seine-et-Oise ou algumas instruções relativas à sua profissão. Passava por um agricultor hábil, mas sua ciência era puramente prática. Assim, em Minoret-Levrault, o moral não desmentia o físico. Falava raramente; e, antes de dizer qualquer coisa, tomava sempre uma pitada de rapé para ter tempo de procurar, não ideias, mas palavras. Conversador, vós o acharíeis imperfeito. Considerando que aquela espécie de elefante sem tromba e sem inteligência chamava-se Minoret-Levrault, não se devia reconhecer, como Sterne, o oculto poder dos nomes, que ora ridicularizam e ora predizem os caracteres? (BALZAC 1990b, p. 21-22). ${ }^{15}$

Por meio da menção a Sterne, Balzac pretendia remeter ao décimo nono capítulo do primeiro livro de $A$ vida e as opiniões do cavalheiro Tristram Shandy (1759). Nele, o narrador em primeira pessoa expõe uma das ideias "fora do comum" de seu pai. Essa dizia respeito à escolha e imposição de nomes de batismo: "Sua opinião [...] era de que há uma espécie de influência mágica que os nomes bons ou maus, conforme os chamava, irresistivelmente imprimem em nosso caráter e em nossa conduta". Segundo Walter Shandy, nomes como Trismegisto e Arquimedes, César e Pompeu inspirariam seus portadores a buscar e a alcançar a grandeza, ao passo que Nily, Sinkin e Nicodemos conduziriam ao abatimento da vontade e ao fracasso. Batizar uma criança de Judas seria condená-la a ser "um miserável e um biltre", a despeito de todos os bons exemplos que os pais pudessem oferecer-lhe. Haveria igualmente nomes neutros, como Jack, Dick e Tom, cujos poderes negativos ou positivos teriam sido destruídos pelo fato de terem existindo "pelo menos tantos patifes e tolos quanto homens dignos e sábios, desde o começo do mundo, que os havia indiferentemente ostentado". Na opinião de Walter, o mais maligno de todos os nomes não era outro senão Tristram, com o qual seu segundo filho fora batizado, para seu maior e contínuo tormento (STERNE 1998, p. 84-88).

\footnotetext{
${ }_{14}$ Originalmente intitulada Les Célibataires, a narrativa foi publicada em 1832 no terceiro tomo das Cenas da vida privada e já contava com o trecho citado. No ano seguinte, foi reclassificada como uma das Cenas da vida provinciana. Somente quando integrada em A comédia humana, onde apareceu em 1843, é que ela recebeu seu título definitivo (MOZET).

15 Depois de sair em Le Messager em 1841, Úrsula Miroüet foi publicada em livro em maio de 1842, com inúmeras modificações. No ano seguinte, sua edição no quinto volume de $A$ comédia humana fez-se sem importantes alterações no texto (MAHIEU).
} 
Em Sterne, a tese do poder mágico do nome sobre o caráter dos indivíduos apareceu como mais um entre os vários disparates sustentados pelo pai de Tristram. Logo no início do capítulo, o narrador chega a prever as várias reações, todas igualmente negativas, dos diferentes leitores à exposição que faria a seguir (STERNE 1998, p. 84). Seja por retirar seu enquadramento negativo, seja por designá-la pelo neologismo de "cognomologia", Balzac estava na verdade utilizando-se da referência ao romancista inglês para elaborar sua própria teoria dos nomes. ${ }^{16}$ Com efeito, suas diversas formulações nos trechos supracitados conduzem à afirmação de uma necessária correspondência entre o nome e a personagem. Longe de serem signos arbitrários reduzidos à função de individualização, os nomes próprios em Balzac são "falantes", eles exprimem algo a respeito dos seres que nomeiam.

Como mostram os trechos citados, a correspondência incidia, seja sobre o ser físico, seja sobre o ser moral da personagem, seja sobre ambos. Fundamentalmente, contudo - e daí a referência preferencial a Sterne -, o nome próprio balzaquiano predestina. A história de uma personagem será a história do destino previsto pelo nome - princípio cuja enunciação se encontra na mais longa reflexão de um narrador balzaquiano a esse respeito:

Nunca vi ninguém, mesmo incluindo os homens notáveis da época, cujo aspecto fosse mais impressionante do que o daquele homem. $\mathrm{O}$ estudo de sua fisionomia despertava uma vaga sensação de piedade, e acabava por provocar uma melancolia quase dolorosa. Existia certa harmonia entre a pessoa e o nome. Aquele Z. que precedia Marcas, que se via no endereço de suas cartas, e que ele nunca esquecia na sua assinatura, essa última letra do alfabeto, oferecia ao espírito um não sei quê de fatal.

MARCAS! Repitam esse nome composto de duas sílabas, e digam se não acham nele uma sinistra ressonância? Não lhes parece que o homem que o porta deva ser martirizado? Conquanto estranho e selvagem, esse nome tem, entretanto, direito a alcançar a posteridade; é de boa composição, pronuncia-se facilmente, tem a brevidade desejada para os nomes célebres. Não é ele tão suave quanto singular? Mas Ihes parece também inacabado? Não me atreveria a afirmar que os nomes não exercem nenhuma influência sobre o destino. Entre os fatos da vida e o nome dos homens, existem concordâncias secretas e inexplicáveis, ou se não desacordos visíveis que surpreendem; revelaram-se com frequência, neste particular, correlações longínquas, porém eficazes. Nosso globo é maciço, não existem soluções de continuidade, tudo nele tem ligações. É bem possível que nos voltemos qualquer dia para as ciências ocultas.

Não veem, na construção do $Z$, uma tendência contrariada? Não representa ele o ziguezague aleatório e caprichoso de uma vida atormentada? Que vento soprou sobre essa letra, que em qualquer língua em que é admitida, encabeça somente cinqüenta palavras? Marcas chamava-se Zeferino. São Zeferino era muito venerado na Bretanha. Marcas era bretão.

Examinem ainda esse nome: Z. Marcas! Toda a vida do homem está na reunião fantástica dessas sete letras. Sete! o mais significativo dos

\footnotetext{
${ }^{16}$ Ver resumo da comunicação oral de Ada Smaniotto, cuja tese de doutorado, em andamento, tem por tema a poética da nomeação em Balzac, em Balzaciales: les rencontres des doctorants sur Balzac. Disponível em: http://www.balzacorama.univ-paris-diderot.fr/balzaciales.html. Acesso em: 24 dez. 2013.
} 
números cabalísticos. O homem morreu aos trinta e cinco anos, de modo que sua vida se compôs de sete lustros. Marcas! Não Ihes dá esse nome a ideia de qualquer coisa preciosa que se quebra numa queda, com ou sem ruído? (BALZAC 1991, p. 319-320).17

Fiel a seu nome, como significante sonoro e gráfico, como nome de santo, Z. Marcas se viu duas vezes apeado do brilhante destino político que almejava, reduzido inicialmente à pobreza e depois à mais infame das mortes, enterrado que foi em uma cova comum.

O romancista referiu-se diretamente a essa característica de sua onomástica no "Prefácio" a Uma filha de Eva (1839). Única menção, em paratextos, ao problema da nomeação das personagens, ela emerge aí nos quadros da habitual mistura de explicitação de pressupostos e autoelogio, corrente em um escritor tão certo de seus feitos. Mais rara era a indicação do respaldo que sua obra merecera junto a um público especial. Nesse prefácio, Balzac afirma que, ao contrário do que sempre pensara, seus esforços artísticos e científicos não lhe proporcionavam apenas a recompensa pessoal pela consciência de um trabalho escrupulosamente realizado, mas sua obra mereceria também o reconhecimento dos eruditos, que teriam expressado satisfação por encontrar nela suas próprias ciências: um médico ilustre ter-se-ia impressionado com a adequada construção do perfil médico das personagens, cujas paixões corresponderiam às respectivas aparências físicas; um erudito teria apontado o estudo sério de questões graves. E outro estudioso teria "observado o cuidado com que os nomes são adaptados às personagens" (BALZAC 1839, p. 31).

Para o autor, a questão da nomeação não remetia, em primeiro lugar, à lógica do nome próprio real. Ela não se destinava expressamente à promoção da verossimilhança da narrativa, não era signo de que o romance fosse mera imitação da realidade. A exemplo da fisiognomonia, a nomeação integrava, para Balzac, o arsenal, a certos títulos científico, que ele mobilizou para construir o mundo ficcional que deveria contar a história da sociedade francesa oitocentista. Assim como as personagens não foram apresentadas como cópias do real, mas como tipos compostos "pela reunião dos traços de múltiplos caracteres homogêneos" (BALZAC 1842, p. 15), seres propriamente ficcionais dotados de baixo mas não menos efetivo grau de generalização frente à concretude do mundo - em suma, como produção do romancista que, para copiar, deve inventar a realidade que reproduz $-{ }^{18}$ o nome próprio participou do esforço de descrição do social na medida em que sua lógica desobedecia àquela do registro civil, no qual um antropônimo não autoriza grandes deduções sobre a pessoa por ele designada. Em Balzac, a nomeação não se reduz a etiqueta designativa, ela é motivada.

\footnotetext{
17 Publicado originalmente em 1840, na Revue Parisienne, Z. Marcas reapareceu no ano seguinte na coletânea coletiva Le fruit défendu, sob o título Mort d'un ambitieux; em 1846, readquiriu o título original ao ser integrado a A comédia humana, entre as "Cenas da vida política" do volume XII. O texto não sofreu alterações ao longo desse período (LAFORGUE).

${ }^{18}$ Embora devedora da interpretação de Jérôme David (2010, especialmente os três primeiros capítulos), essa abordagem da questão do nome próprio balzaquiano não leva em conta, por desnecessárias à problemática, as diferenças na formulação e nos usos que Balzac fez da noção de tipicidade, enfatizadas e brilhantemente analisadas por David; o ponto essencial consiste, conforme se nota, na crítica da tese de um realismo ingênuo em Balzac.
} 
Em linguística, conforme assinalado, o nome próprio é descrito como um tipo particular de signo, composto apenas por significante (o som ou a grafia da palavra) e referente, destituído de sentido, logo, de significado. Em literatura, contudo, o nome próprio pode assumir uma significação - ser motivado. A motivação do nome próprio da personagem ficcional não é uma novidade do romance balzaquiano; a invenção dos nomes à antiga nas comédias e nos romances do século XVII levava mormente em consideração o significado dos radicais utilizados - em Molière, para ficar apenas com este exemplo, Géronte designa o tipo do homem velho. No romance setecentista, a prática de se inventar nomes realistas reduziu a nomeação motivada a fenômeno marginal (DEMORIS). Ao reconduzi-la ao centro do romance, Balzac não deixou de escrever um capítulo inédito da onomástica romanesca; associando realismo e motivação, o nome próprio tornou-se, com ele, ilusão de verdade da personagem romanesca:

Tratado como um signo espesso, pleno de sentido, o nome próprio balzaquiano torna-se a garantia da plenitude substantiva de uma personagem. Seguindo-a ao longo de todo seu trajeto narrativo, envolvendo-a, saturando-a em todas as ocasiões de sua opaca muralha de letras e de sons, ele é como sua carne de linguagem, seu corpo de palavras. Munido de um tal tesouro onomástico, o portador do nome romanesco encontra-se magicamente dotado de uma espessura prévia de vida que depende do silogismo sobre o qual todo realismo apoia-se, que quer que a todo significante onomástico feito segundo as normas corresponda um indivíduo de carne e osso (DIAZ 1981, p. 46, tradução nossa)..19

\section{Um topos literário}

Nada evidencia melhor a ruptura introduzida por Balzac na onomástica romanesca do que a separação entre o destino da obra balzaquiana e o destino do nome próprio no romance oitocentista. De seus mais duros críticos aos mais complacentes herdeiros, passando por aqueles que alimentaram uma atitude ambígua face ao seu projeto literário e à sua literatura, os mais diferentes romancistas do século XIX tanto deram provas de que o nome próprio havia se tornado uma questão fundamental do gênero quanto praticaram uma nomeação motivada.

Em relação a Balzac, Flaubert passou de uma admiração quase sem restrições para uma crítica cada vez mais severa. Em suas cartas, afirmou mais de uma vez que o autor de Eugênia Grandet não sabia escrever, que não tinha estilo; ironizou a admiração dele por Walter Scott; traçou a imagem de um autor obcecado com o Dinheiro e a Glória e pouco preocupado com a Arte e o Belo; e chegou a sentenciar: "um imenso sujeito, mas de segunda ordem" (GUINOT 2010, p. 53). Além disso, Bouvard e Pécuchet, as duas encarnações romanescas da tolice, maravilharam-se com a obra de Balzac, ao mesmo tempo em que ironizaram seus excessos:

\footnotetext{
${ }^{19}$ No original: "Traité comme un signe épais, plein de sens, le nom propre balzacien se fait le garant de la plénitude substantive d'un personnage. Le suivant tout au long de son trajet narratif, l'entourant, le lestant en toutes occasions de son opaque rempart de lettres et de sons, il est comme sa chair de langue, son corps de mots. Doué d'un tel trésor onomastique, le porte-nom romanesque se trouve magiquement pourvu d'une épaisseur préalable de vie qui tient au syllogisme implicite sur lequel tout réalisme s'appuie, qui veut qu'à tout signifiant onomastique fait selon les normes corresponde un individu de chair et d'os".
} 
Aspectos novos surgiram nas coisas mais banais. Eles não haviam suspeitado que a vida moderna fosse tão profunda.

- Que observador!, exclamava Bouvard.

- Já eu, acho-o quimérico, acabou dizendo Pécuchet. Ele acredita nas ciências ocultas, na monarquia, na nobreza, fascina-se com os velhacos, remexe-vos os milhões como se fossem centavos, e seus burgueses não são burgueses, mas colossos. Por que inflar o que é raso e descrever tantas tolices? Ele fez um romance sobre a química, um outro sobre o Banco, um outro sobre as máquinas de impressão. [...]. Teremos outros sobre todas as profissões e sobre todas as províncias, depois sobre todas as cidades e os andares de cada casa e cada indivíduo, o que já não será literatura, mas estatística ou etnografia (GUINOT 2010, p. 53-54). ${ }^{20}$

Valores e posições ideológicas do autor, modo de construção das personagens e até a característica número um do projeto literário balzaquiano - sua exaustividade - foram submetidos à derrisão.

Esse mesmo Flaubert deu provas de uma preocupação autenticamente balzaquiana com os nomes de suas personagens. Em carta a Louis Bonenfant, em 1868, ajuizou que "o nome próprio é uma coisa extremamente importante em um romance, uma coisa capital. Assim como não se pode mudar a cor da pele, não se pode mudar o nome de um personagem. É desejar embranquecer um negro" (GUINOT 2010, p. 505). ${ }^{21}$ Em outra ocasião, o autor deu provas de um alvoroço digno de um comentário irônico de Pécuchet diante da possibilidade de ter de abrir mão de um antropônimo romanesco. A anedota foi narrada por Zola, em um texto publicado no Le Messager de l'Europe pouco depois da morte do romancista, ocorrida em maio de 1880. Como almoçassem na casa do editor Georges Charpentier e a conversa recaísse nos nomes, Zola contou aos convivas o nome excelente que encontrara para uma personagem de Sua excelência Eugênio Rougon (Son Excellence Eugène Rougon) (1876), em curso de redação naquele momento. Ele não era outro senão Bouvard! Tomado de súbito de um ar bizarro, Flaubert, apenas deixaram a mesa, levou Zola até o fundo do jardim, onde, "fortemente emocionado", suplicou-lhe que the cedesse aquele nome. "Eu o cedi rindo - contou o escritor. Mas ele permanecia sério, muito sensibilizado, e repetia que não teria continuado seu livro se eu tivesse mantido o nome. Para ele, toda a obra estava nesses dois nomes: Bouvard e Pécuchet. Ele já não a via sem ambos" (GUINOT 2010, p. 505-506). ${ }^{22}$ Dois anos mais tarde, Zola ofereceria em sua carta a Élie de Cyon o princípio que se pode depreender daquela anedota. Então, ele afirmou que "Gustave Flaubert levava

\footnotetext{
${ }^{20}$ No original: "Dans les choses les plus banales, des aspects nouveaux surgirent. Ils n'avaient pas soupçonné la vie moderne aussi profonde. / - Quel observateur! s'écriait Bouvard. / - Moi je le trouve chimérique, finit par dire Pécuchet. Il croit aux sciences occultes, à la monarchie, à la noblesse, est ébloui par les coquins, vous rémue les millions comme des centimes, et ses bourgeois ne son pas des bourgeois, mais des colosses. Pourquoi gonfler ce qui est plat, et décrire tant de sottises? Il a fait un roman sur la chimie, un autre sur la Banque, un autre sur les machines à imprimer. [...]. Nous en aurons sur tous les métiers et sur toutes les provinces, puis sur toutes les villes et les étages de chaque maison et chaque individu, ce qui ne sera plus de la littérature, mais de la statistique ou de l'ethnographie".

${ }^{21}$ No original: "Un nom propre est une chose extrêmement important dans un roman, une chose capitale. On ne peut pas plus changer un personnage de nom que de peau. C'est vouloir blanchir un nègre".

22 "Je le lui abandonnai en riant. Mais il restait sérieux, très touché, et il répétait qu'il n'aurait pas continué son livre, si j'avais gardé le nom. Pour lui, toute l'oeuvre était dans ces deux noms: Bouvard et Pécuchet. Il ne la voyait plus sans eux".
} 
assim a religião do nome ao ponto de dizer que, se nome deixasse de existir, também o romance deixava de existir" (GUINOT 2000, p. 506). ${ }^{23}$

O pai do naturalismo, por sua vez, inseriu na boca de duas de suas personagens de $O$ regabofe (La Curée) (1871) uma reflexão sobre os nomes cujo sabor não nos é menos familiar:

- Tenho a intenção de mudar de nome, disse ele finalmente; você deveria fazer o mesmo... Teríamos menos incômodos.

- Como você quiser, respondeu tranquilamente Aristide.

- Você não precisará se preocupar com nada, eu me encarrego das formalidades... Você quer se chamar Sicardot, como sua mulher?

Aristide levou os olhos ao teto, repetindo, escutando a música das sílabas:

"Sicardot..., Aristide Sicardot... Pelo amor de Deus, não; é mandrião e soa a falência.

- Procure outra coisa então, disse Eugène.

- Eu preferiria Sicard muito simplesmente, replicou o outro depois de um silêncio; Aristide Sicard..., não está mal... não é? talvez um pouco alegre...

Ele devaneou ainda um momento e, com um ar triunfante:

- Consegui, encontrei, exclamou ele... Saccard, Aristide Saccard!... com dois " $c$ "... Hein! Tem dinheiro nesse nome; dir-se-ia que se contam moedas de cinco francos. ${ }^{24}$

Eugène era um gozador implacável; despediu seu irmão dizendo-Ihe, com um sorriso:

- Sim, um nome para ir para as galés ou para ganhar milhões (MITERRAND 2012, p. 575-576, tradução nossa). ${ }^{25}$

Sim, um nome para ganhar milhões. Funcionário da prefeitura de Paris graças justamente a seu irmão Eugène Rougon, ministro sob o Segundo Império, Aristide Saccard usaria informações privilegiadas sobre a reforma urbana de Haussman para enriquecer por meio da especulação imobiliária.

Pouco conhecido do público brasileiro atual, o romancista Jules Barbey d'Aurevilly (1808-1889), dândi convertido ao catolicismo reacionário e ao absolutismo, foi um romancista de destaque na França da segunda metade do século XIX. Inimigo declarado de Flaubert, sobre quem escreveu que "soube fazer um livro, mas não dois" (GUINOT 2010, p. 56-57), e pouco apreciado por Zola, ele nutriu grande admiração por Balzac. Como na obra desse último autor, os nomes em Barbey chamam de imediato a atenção, de tal modo são inventados de propósito para dizer o ser e o destino de suas personagens. Entre elas, encontram-se Martyre, prenome da Madame de Mendoze (Une

\footnotetext{
23 "Gustave Flaubert poussait ainsi la religion du nom au point de dire que, le nom n'existant plus, le roman n'existait plus".

24 O termo original é "cent sous". O "sou" era equivalente a cinco centavos de franco.

25 No original: "- Je compte changer de nom, dit-il enfin, tu devrais en faire autant... Nous nous gênerions moins. /- Comme tu voudras, répondit tranquilement Aristide/ - Tu n'auras à t'occuper de rien, je me charge des formalités... Veux-tu t'appeler Sicardot, du nom de ta femme? / Aristide leva les yeux au plafond, répetant, écoutant la musique des syllabes: / 'Sicardot..., Aristide Sicardot... Ma foi, non; c'est ganache et ça sent la faillite. / - Cherche autre chose alors, dit Eugène. / - J'aimerais mieux Sicard tout court, reprit l'autre après un silence; Aristide Sicard..., pas trop mal... n'est-ce pas? peut-être un peu gai... / Il rêva un instant encore, et, d'un air triomphant: / - J'y suis, j'ai trouvé, cria-t-il... Saccard, Aristide Saccard!... avec deux c... Hein! Il y a de l'argent dans ce nom-là; on dirait que l'on compte des pièces de cent sous. / Eugène avait la plaisanterie féroce. Il congédia son frére en lui disant, avec un sourire: / - Oui, un nom à aller au bagne ou à gagner des millions".
} 
vieille maîtresse, 1851), que será martirizada por Rino; Jeanne de Feuardent (L'ensorcellée, 1854), queimada em seu braseiro; o tortuoso doutor Torty; a bela e impetuosa Hauteclaire Stassin, que se rebaixou na obscuridade; Rochefort, que é duplamente forte (nas novelas de Les Diaboliques, 1874), etc. Verdadeiro "amante dos nomes", Barbey d'Aurevilly também os colecionava. Em sua correspondência com Trébutien, melhor amigo, primeiro leitor e editor, o romancista pediu insistentemente que ele the fornecesse listas de nomes normandos - Barbey d'Aurevilly desejava fazer da Normandia, sua terra natal, o cenário de suas obras:

Envie-me "alguns belos nomes de homens e de mulheres normandos (nomes de batismo que possuam bem o caráter do país)"; Se você puder encontrar para mim, no meio de alguma papelada, alguns belos sobrenomes, sobrenomes desaparecidos, separe-os sempre para mim (DODILLE 1981, p. 41). ${ }^{26}$

Flaubert, Zola, Barbey d'Aurevilly... Os exemplos poderiam ser multiplicados, a tal ponto a motivação do nome próprio tornou-se um "topos literário" (DODILLE 1981, p. 38). Esse "lugar-comum do nome" na poética do romance oitocentista recobre, não obstante, poéticas romanescas e onomásticas muito singulares, como no Brasil se poderia ver a propósito do romance de José de Alencar ou do de Machado de Assis, um escritor consciente o bastante da força desse topos para manipulá-lo de maneira absolutamente original.

\section{Referências bibliográficas}

BALZAC. O cura de Tours. In:

A Comédia Humana. Volume V. Estudos de costumes. Cenas da Vida Provinciana. Orientação, introdução e notas de Paulo Ronái. São Paulo: Globo, 1990a.

. Úrsula Mirouët. In:

A Comédia Humana. Volume V. Estudos de costumes. Cenas da Vida Provinciana. Orientação, introdução e notas de Paulo Ronái. São Paulo: Globo, 1990b.

Z. Marcas. In:

A Comédia Humana. Volume XII: Estudos de costumes: cenas da vida política; cenas da vida militar. Orientação, introdução e notas de Paulo Rónai. São Paulo: Globo, 1991.

- Gobseck (En ligne) Paris: Furne, 1842. In:

La Comédie

Humaine. Édition critique en ligne. Disponível em: http://artflsrv02. uchicago.edu/cgi-bin/philologic/getobject.pl?c.68:1.balzacNEW. Acesso em: 27 dez. 2013.

- La peau de chagrin (En ligne). Paris: Furne, 1845. In: La

Comédie Humaine. Édition critique en ligne. Disponível em: http://

\footnotetext{
26 "Envoyez-moi 'quelques noms d'hommes et de femmes Normands (noms de baptême ayant bien le caractère du pays)'. Si vous trouverez en paperassant pour moi quelques beaux noms de familles, de famille éteinte, mettez-les moi toujours de côté'". Na "Introdução" ao volume organizado por ela e recentemente publicado na coleção Quarto, Judith Lyon-Caen (2013) também abordou o problema do nome próprio em Barbey d'Aurevilly.
} 
artflsrv02.uchicago.edu/cgi-bin/philologic/getobject.pl?c.68:1. balzacNEW. Acesso em: 20 out. 2013.

. La Recherche de I'Absolu. Paris: Furne, 1845. In: - La Comédie

Humaine. Édition critique en ligne. Disponível em: http://artflsrv02. uchicago.edu/cgi-bin/philologic/getobject.pl?c.72:1.balzacNEW. Acesso em: 27 dez. 2013.

. "Avertissement" du Gars. In: Écrits sur le roman: anthologie. Textes choisis, presentés et annotés par Stéphane Vachon. Paris: Le Livre de Poche, 2000a, p. 48-70.

. Lettre à Madame Hanska du 26 octobre 1834. In:

Écrits sur

le roman: anthologie. Textes choisis, presentés et annotés par Stéphane Vachon. Paris: Le Livre de Poche, 2000b, p. 81-85.

- Préface. In:

Même histoire: études des moeurs au XIXe. siècle. Scènes de la vie privée. Quatrième volume. Paris: Madame CharlesBéchet, 1834, p. 7-9. Disponível em: http://gallica.bnf.fr/ark:/12148/ btv1b8617168x. Acesso em: 21 out. 2013.

. Préface. In: Études des moeurs au XIXe. siècle. Tome VIII. Seconde série: Scènes de la vie privée. Quatrième Volume. Paris: Werdet, Libraire-Éditeur, 1837, p. III-XII. Disponível em: http://gallica. bnf.fr/ark:/12148/btv1b8617172t. Acesso em: 15 out. 2003. Comédie Humaine, premier volume. Première partie, Études des moeurs. Premier Livre. Scènes de la vie privée, Tome I. Paris: Furne, J.J. Doubochet et cie, J. Hetzel et Paulin, 1842, p. 27. Disponível em: http://gallica.bnf. fr/ark:/12148/bpt6k61165647. Acesso em: 25 out. 2013.

Préface. In:

Une fille d'Ève: scène de la vie privée. Paris: Hippolyte Souverain, 1839. Disponível em: http://gallica.bnf.fr/ ark:/12148/bpt6k113380x. Acesso em: 20 maio 2013.

CAMPOS, Raquel Machado Gonçalves. Uma poética da homonímia: o problema do nome próprio em Machado de Assis. 2014. 437f. Tese (Doutorado em História Social). Programa de Pós-Graduação em História Social. Faculdade de História, Universidade Federal do Rio de Janeiro, Rio de Janeiro, 2014.

DAVID, Jerôme. Balzac, une éthique de la description. Paris: Honoré Champion, 2010.

DAVIN, Félix. Introduction. In: M. DE BALZAC. Études des moeurs au XIXe. siècle. Scènes de la vie privée. Premier volume. Paris: Madame CharlesBéchet, Éditeur, 1835, p. 1-32. Disponível em: http://gallica.bnf.fr/ ark:/12148/bpt6k690200. Acesso em: 15 out. 2013.

DEMORIS, René. "La symbolique du nom des personnes dans 'Les liaisons dangereuses'". Littérature (Sémiotiques du roman), n. 36, p. 104-119, 1979. Disponível em: www.persée.fr. Acesso em: 29 nov. 2013. 
DIAZ, José-Luiz. Balzac \& la scène romantique du nom propre (II). $\mathbf{3 4}$ 44, n. 8, outono de 1981.

DIDEROT, Denis. Éloge de Richardson. In:

Oeuvres de Diderot, publiées sur les manuscrits de I'Auteur, par Jacques-André Naigeon. Tomo IX. Paris: Deterville, Libraire, ano VIII (1800). Disponível em: http://gallica.bnf.fr/ark:/12148/bpt6k206083x. Acesso em: 20 nov. 2013.

DODILLE, Norbert. L'amateur des noms. Essai sur I'onomastique aurevillienne. In: BONNEFIS, Philippe; BUISINE, Alain (orgs.). La Chose Capitale: essai sur les noms de Barbey, Barthes, Bloy, Borel, Huysmans, Maupassant, Paulhan. Lille: Presses de I'Université de Lille 3, 1981, p. 37-69.

DUCHET, Claude. De A à Z: Balzac, faiseur de noms. Magazine Littéraire, $\mathrm{n}$. 373, p. 48-51, 1999.

FRAPPIER-MAZUR. La Recherche de I'Absolu: notice. In: BALZAC. La Comédie Humaine. Édition critique en ligne. Disponível em: http://www.v1.paris. $\mathrm{fr} /$ commun/v2asp/musees/balzac/furne/notices/recherchabsolu.htm. Acesso em: 27 dez. 2013.

GOULEMOT, Jean-Marie. As práticas literárias ou a publicidade do privado. In: CHARTIER, Roger (org.). História da vida privada: da Renascença à Europa das Luzes. São Paulo: Companhia das Letras, 1991, p. 371-405.

GUINOT, Jean-Benoît (org.). Dictionnaire Flaubert. Paris: CNRS Éditions, 2010.

HAMON, Philippe. Pour un statut sémiologique du personnage. In: BARTHES, Roland et alii. Poétique du récit. Paris: Seuil, 1977, p. 115-180.

LAFORGUE, Pierre. "Z. Marcas: Notice". In: BALZAC. La Comédie Humaine: édition critique en ligne. Disponível em: http://www.v1.paris.fr/commun/ v2asp/musees/balzac/furne/notices/z_marcas.htm. Acesso em: $29 \mathrm{dez}$. 2013.

LEONARD, Martine. Noms propres et illusion réaliste: de Balzac à Zola. 34-44, n. 7: Noms propres, p. 81-91, 1980.

LOVENJOUL, Charles de Spoelberch de. A propos de la recherche et de la physionomie des noms chez Balzac. In: Un roman d'amour. Réimpression de l'édition de Paris, 1896. Genève: Slatkine Reprints, 1973, p. 111-159. Disponível em: http://gallica.bnf.fr/ark:/12148/bpt6k8837j. Acesso em: 22 dez. 2013.

LYON-CAEN, Judith. Situation du roman, années 1830-1840. In: . La lecture et la vie: les usages du roman au temps de Balzac. Paris: Tallandier, 2006.

. Introduction. In: BARBEY D'AUREVILLY. Romans. Édition établie et présentée par Judith Lyon-Caen. Paris: Gallimard, 2013, p. 9-18. 
MAHIEU, Raymond. "Ursule Mirouet: notice". In: BALZAC. La Comédie Humaine. Édition critique en ligne. Disponível em: http://www.v1.paris.fr/commun/ v2asp/musees/balzac/furne/notices/ursule_mirouet.htm. Acesso em: 27 dez. 2013.

MALEUVRE, Didier. Gobseck: Notice. In: BALZAC. La Comédie Humaine. Édition critique en ligne. Disponível em: http://www.v1.paris.fr/commun/v2asp/ musees/balzac/furne/notices/gobseck.htm. Acesso em: 27 dez. 2013.

MILLER, Isabelle. La Femme de Trente Ans: notice. In: BALZAC. La Comédie Humaine. Édition critique en ligne. Disponível em: http://www.v1.paris. $\mathrm{fr} /$ commun/v2asp/musees/balzac/furne/notices/femme_de_trente_ans. htm. Acesso em: 19 out. 2013.

MITTERAND, Henri. Autodictionnaire Zola. Paris: Omnibus, 2012.

MOZET, Nicole. Le curé de Tours: notice. In: BALZAC. La Comédie Humaine. Édition critique en ligne. Disponível em: http://www.v1.paris.fr/commun/ v2asp/musees/balzac/furne/notices/cure_de_tours.htm. Acesso em: 10 out. 2013.

PASSOS, Gilberto Pinheiro. Machado, leitor de Balzac. In: Cintilações

francesas: Revista da Sociedade Filomática, Machado de Assis e José de Alencar. São Paulo: Nankin Editorial, 2006.

POMMIER, Jean. Comment Balzac a nommé ses personnages. Cahier de I'Association Internationale des Études Françaises, n. 35, 1953. Disponível em: http://www.persee.fr/web/revues/home/prescript/article/ caief_0571-5865_1953_num_3_1_2035. Acesso em: 11 jun. 2013.

RIGOLOT, François. Introduction. In: Poétique et onomastique. Genève: Librairie Droz, 1977, p. 11-24.

STERNE, Laurence. A vida e as opiniões do cavalheiro Tristram Shandy. Tradução, introdução e notas de José Paulo Paes. $2^{a}$ edição corrigida. São Paulo: Companhia das Letras, 1998.

SURVILLE, Madame Laure de. Balzac, sa vie et ses oeuvres d'après sa correspondance. Paris: Librairie Nouvelle: Jaccottet, Bourdillat et cie., 1858, p. 181-182. Disponível em: http://gallica.bnf.fr/ark:/12148/ bpt6k114343z. Acesso em: 10 out. 2013.

TOURNIER, Isabelle. Le retour des personnages. In: BALZAC. La Comédie Humaine. Édition critique en ligne. Disponível em: http://www. v1.paris.fr/commun/v2asp/musees/balzac/furne/fiches/retour.htm. Acesso em: 19 out. 2013.

VACHON, Stéphane. Balzac théoricien du roman. In: BALZAC. Écrits sur le roman: anthologie. Paris: Le Livre de Poche, 2000, p. 9-36. 